\title{
Intraventricular Ganglioglioma Presenting with Spontaneous Hemorrhage
}

\author{
Ganglioglioma Intraventricular Diagnosticado por \\ Hemorragia Espontânea
}

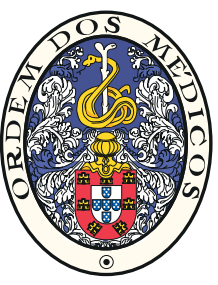

\author{
Alexandre Rainha CAMPOS $\square^{1,4}$, Luísa BISCOITO ${ }^{2,4}$, Maria Gabriela GASPARINHO 3,4 \\ Acta Med Port 2018 Mar;31(3):170-175 - https://doi.org/10.20344/amp.8943
}

\section{ABSTRACT}

Intraventricular gangliogliomas presenting with spontaneous hemorrhage are rare. Due to high density of important tracts lateral to the ventricular atrium, the intraparietal trans sulcal approach is a good option to remove lesions in this location. These tracts are displaced and sometimes destroyed by the presence of large masses. A 33-year-old male presented with a sudden headache and a generalized seizure. He had a left visual field hemianopia and left visual field neglect. Brain computer tomography and magnetic resonance imaging revealed a hemorrhagic tumor located in his right atrium. With the help of tractography an optimal corridor to the tumor through the intraparietal sulcus was planned. Gross total removal of a ganglioglioma was possible with recovery of visual impairment and control of epilepsy. The efficacy in using tractography as a planning tool for safe tumor removal is demonstrated with clinical, imagiological and histological data, and a surgical video.

Keywords: Cerebral Ventricle Neoplasms; Diffusion Tensor Imaging; Epilepsy; Ganglioglioma/surgery

\section{RESUMO}

Os gangliogliomas Intraventriculares com hemorragia espontânea são raros. Devido à densidade elevada de tractos importantes localizados lateralmente ao átrio ventricular, o sulco intraparietal é a via preferencial de acesso para remoção de lesões nesta localização. Um homem de 33 anos recorreu à urgência por cefaleia súbita e crise tónico-clónica generalizada. No exame neurológico, apresentava hemianopsia homónima esquerda e negligência visual esquerda. Realizou tomografia computorizada cranioencefálica e ressonância magnética que revelaram lesão ocupando espaço com hemorragia, localizada no átrio do ventrículo lateral direito. $O$ estudo por tractografia permitiu estabelecer o corredor ideal de acesso ao tumor através do sulco intraparietal. A remoção total do ganglioglioma foi possível sem instalação de défices e com recuperação do défice visual e controle das crises epilépticas. A eficácia do uso da tractografia como ferramenta de planeamento para remoção segura de tumores é aqui apresentada com detalhes clínicos, neurorradiológicos, neuropatológicos e um vídeo cirúrgico.

Palavras-chave: Epilepsia; Ganglioglioma/cirurgia; Imagem de Tensor de Difusão; Neoplasias do Ventrículo Cerebral

\section{INTRODUCTION}

Gangliogliomas are rare brain tumors and mostly benign $(86 \%)$. They appear in children and young adults [22.1 \pm 11.2 years (range: 8 months -67 years)] and are usually located in the temporal lobes $(71.3 \%))^{1-4}$ The most common presenting symptom is seizure $(80 \%-100 \%)$ with hemorrhage reported very seldom. ${ }^{5,6}$ Intraventricular gangliogliomas are also very rare with only 21 reported cases in a recent review. ${ }^{7}$ In 2010, there was a report of a lateral ventricle ganglioglioma presented with bleeding and rapidly progressive increased intracranial pressure symptoms. The authors referred to another case in a review from 2002 but there is insufficient data about the characteristics of the tumor, except for the clinical presentation with simple partial seizures. ${ }^{5}$

The surgical access to the atrium of the lateral ventricles must be chosen depending on tumor location and its feeding vessels but should also account for intra and inter hemispheric white matter tracts in order to preserve the most important ones. ${ }^{8}$

The parietal lobe, lateral to the atrium, has an important confluent of white matter tracts (TPFIA - temporo-parietal fiber intersection area) ${ }^{9}$ (Fig. 1A), which in the right hemisphere is responsible for functions such as attention, visual perception (perceiving and processing information from left visual field), reasoning and problem solving, memory, social communication (ex. metaphors and joke interpretation, etc.), organization, insight and orientation. ${ }^{10}$ In the normal brain, we know where these tracts are but, with the presence of large tumors, they can be displaced and distorted.

The magnetic resonance imaging (MRI) of the brain with its advanced techniques, namely diffusion-weighted imaging (DWI), and specially diffusion tensor imaging (DTI), allows the surgeon to understand how fiber distortion occurs in each individual patient (Fig. 1B). With careful planning, the most important white matter tracts that connect different parts of the brain and the central nervous system can be identified by tractography (Fig.s 1C-E).

In the current report, we describe a rare tumor with an unusual location, presenting symptoms and imaging characteristics. It is illustrated with images used for planning and a video showing some steps of the surgery (Video 1).

1. Neurosurgery Unit. Hospital CUF Descobertas. Lisboa. Portugal.

2. Imaging Unit. Hospital CUF Infante Santo. Lisboa. Portugal.

3. Anatomical Pathology Unit. Hospital CUF Descobertas. Lisboa. Portugal.

4. Instituto CUF de Oncologia. Lisboa. Portugal.

$\bowtie$ Autor correspondente: Alexandre Rainha Campos. alexandre.campos@jmellosaude.pt

Recebido: 12 de março de 2017 - Aceite: 18 de outubro de 2017 | Copyright @ Ordem dos Médicos 2017 

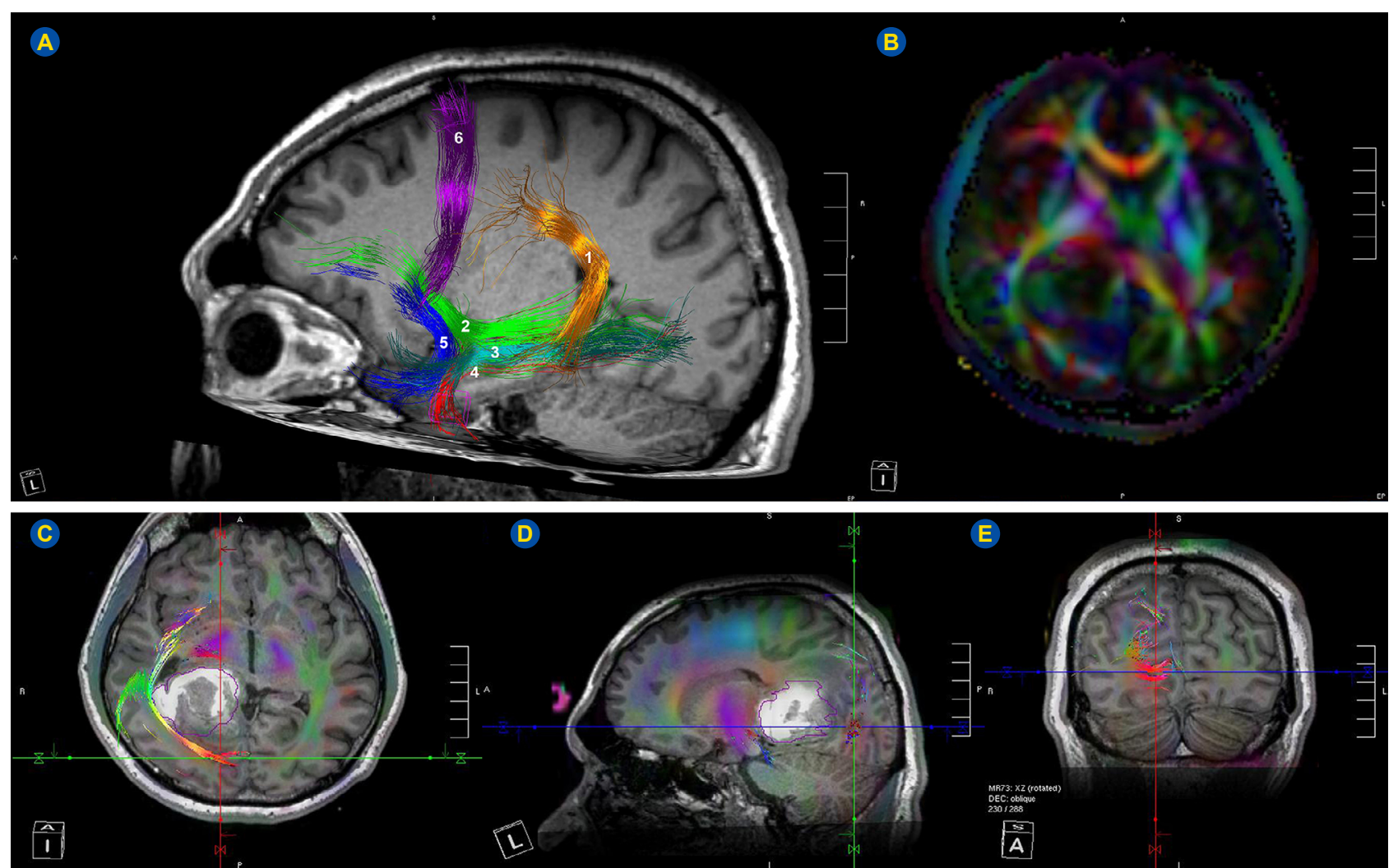

Figure 1 - Processed images with tractography of some intra-hemispheric tracts (A): 1 - arcuate fasciculus, 2 - inferior fronto-occipital fasciculus (IFOF), 3 - middle longitudinal fasciculus, 4 - inferior longitudinal fasciculus, 5 - unciform fasciculus, 6 - frontal aslant tract; The colour map shows the directions of the diffusion in $x, y$ and $z$ space, with the colours red, blue, and green, respectively (B); relationship between tumor and optic radiations in axial (C), sagittal (D) and coronal plane (E) with tractography fused with T1 MRI.

TPFIA: temporo-parietal fiber intersection area

\section{CASE REPORT}

A 33-year-old male, without relevant past medical history, was brought to the emergency department after a sudden headache followed by a generalized seizure. The neurologic examination showed a left visual field hemianopia and left visual neglect. He started on levetiracetam and dexamethasone with improvement of his symptoms.

A brain computer tomography (CT scan) and MRI showed a lesion with $37 \times 42 \mathrm{~mm}$ in the right atrium, hyperdense in the CT, with iso to low signal on T1-weighted MRI and moderate hyper-signal on T2-weighted MRI with slight gadolinium enhancement. The lesion was in close correlation with the posterior fornix, hippocampal tail, choroidal plexus and right extremity of corpus callosum (splenium fibers). These findings were suggestive of a hemorrhagic glial tumor. The tumor had also a cystic area adjacent to its upper limit $(33 \times 31 \mathrm{~mm})$. The mass effect was moderate and there were no signs of acute hydrocephalus (Fig. 2).

To plan the surgical removal of the lesion, a brain MRI with DTI was acquired (Siemens MAGNETOM Skyra 3T, 20 gradient directions, b-values of 0 and $1000 \mathrm{sec} / \mathrm{m}^{2}, 128 \mathrm{x}$ 128 matrix, FOV $=230 \mathrm{~mm}$ ). Post processing was done by the surgeon on a Medtronic ${ }^{\circledR}$ StealthStation $S 7^{\circledR}$ planning station with StealthViz ${ }^{\mathrm{TM}}$ software (version 1.3.0.34, Visage Imaging, Inc.) (Fig.s 1, 3 and 4). With this software, the tumor and the cyst were segmented. After this, the tracts were built using the regions of interest around the tumor where they were expected to be displaced to. The inferior fronto-occipital fascicle (IFOF), optic radiations and arcuate fasciculus where identified and the approach to the tumor was planned to avoid any injury to these fibers. The volumes were created and exported to the intraoperative station. A Medtronic StealthStation $\mathrm{iNav}^{\circledR}$ was used for fusion and surgery. Arcuate fasciculus was displaced laterally and inferiorly, optic radiations were displaced laterally and an optimal corridor to the tumor was confirmed to be through the intraparietal sulcus (Video 1).

After craniotomy, a parietal approach was performed through the intraparietal sulcus until the cyst was reached. The cyst contained a citreous fluid. Below this, a hemorrhage was identified and removed from inside the ventricle. Finally, the grayish tumor nodule was removed with meticulous circumferential dissection from the ependymal lining after some debulking with a Cavitron Ultrasonic Aspirator (CUSA Excel; Valleylab, Boulder, CO, USA) with a $23 \mathrm{kHz}$ handpiece. Part of this tumor was attached to choroidal plexus. After tumor and hematoma debulking and resection, the anatomic structures in close correlation with the tumor were identified and preserved (hippocampal tail, fimbria/ fornix, thalamus, optic radiations, primary visual cortex) (Fig. 6 and Video 1). A gross total removal of the tumor was achieved.

Histological analysis revealed a mixed tumor, with 


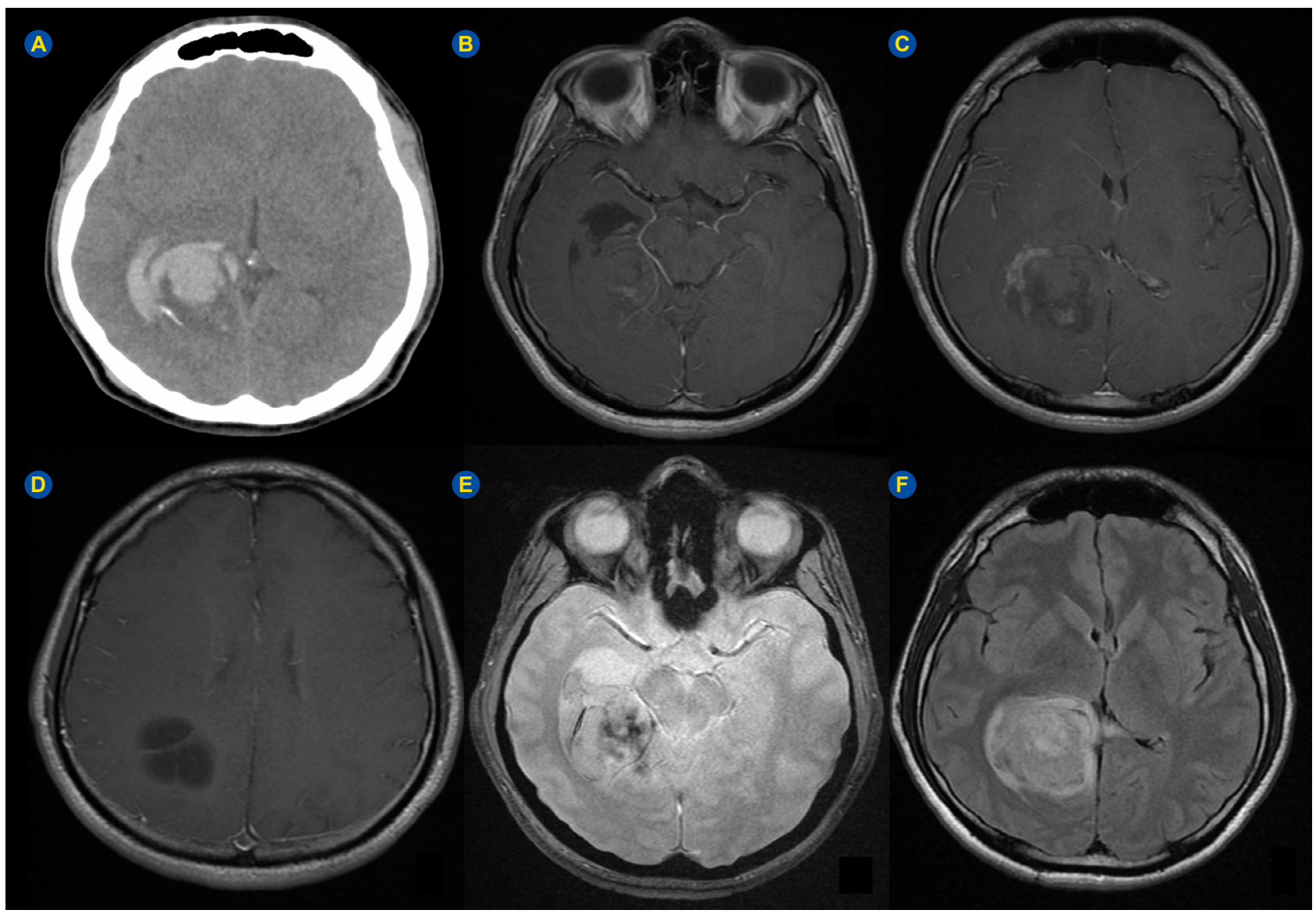

Figure 2 - Preoperative images. Axial CT - hemorrhagic lesion located in the right atrium (A); Axial T1-weighted MRI with gadolinium (BD). A clear relationship between tumor and choroidal plexus is evident and of note is also the cyst on top of the intraventricular tumor (D); Axial T2* MRI to demonstrate hematic deposits (E); Axial FLAIR MRI (F).

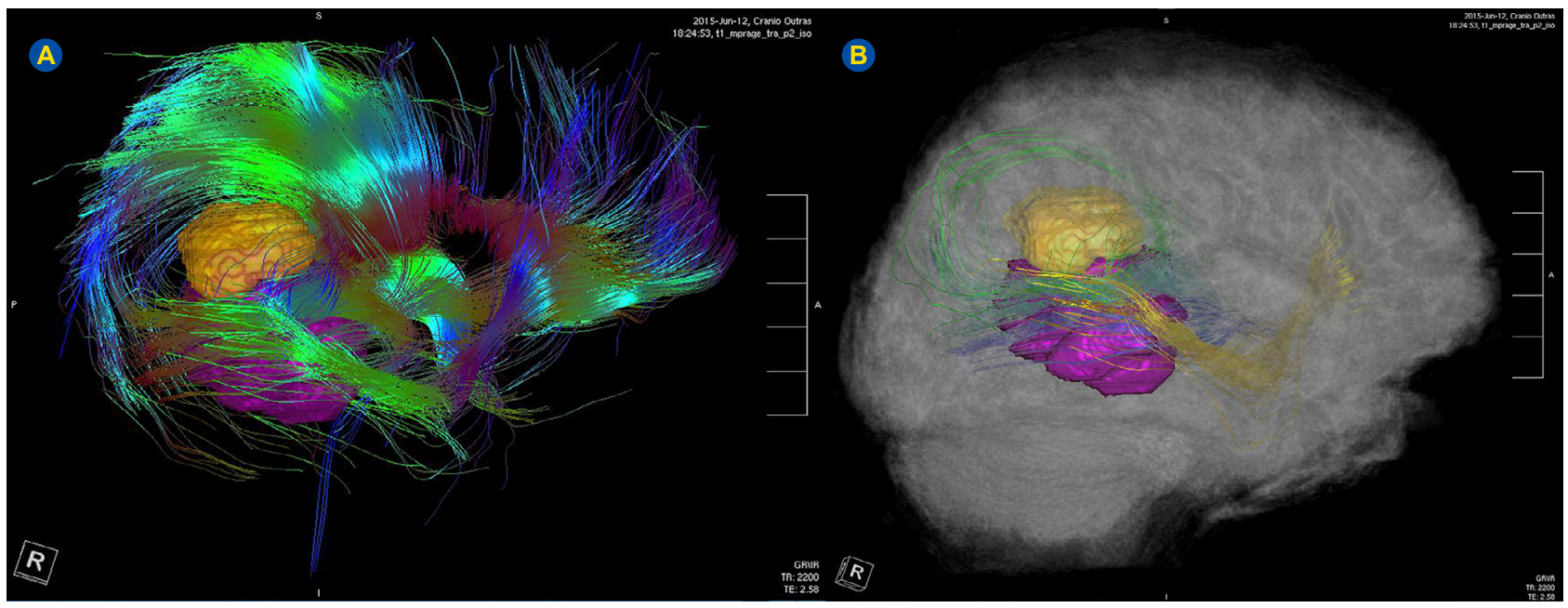

Figure 3 - Three-dimensional reconstruction of tumor (magenta), cyst (dark-yellow) and fiber tracts (colour coded - see Fig. 1B) close to tumor (A); three-dimensional reconstruction of brain (gray), tumor (pink), cyst (dark-yellow), IFOF (yellow - see Fig. 1A), optic radiations (blue) and arcuate fasciculus (green - deviated laterally) (B).

a glial component pilocytic astrocytoma-like, displaying piloid areas (GFAP+, p53 -), Rosenthal fibers, microcysts and eosinophilic granular bodies, and a second neuronal component, diffusely distributed, with ganglionar cells in different stages of differentiation, chromogranin+/ synaptophysin+/CD34+. Abundant capillary type vascular proliferation, intra-tumoral hemorrhage and rich reticulin network were also present. Proliferative index (Ki-67) was very low (<2\%) (Fig. 5). The neuropathologic classification of the tumor was ganglioglioma (grade I WHO).

The postoperative period was uneventful without new neurological deficits. The patient remains asymptomatic after 17 months of follow-up without signs of recurrence. He stopped anticonvulsive therapy two months after surgery 


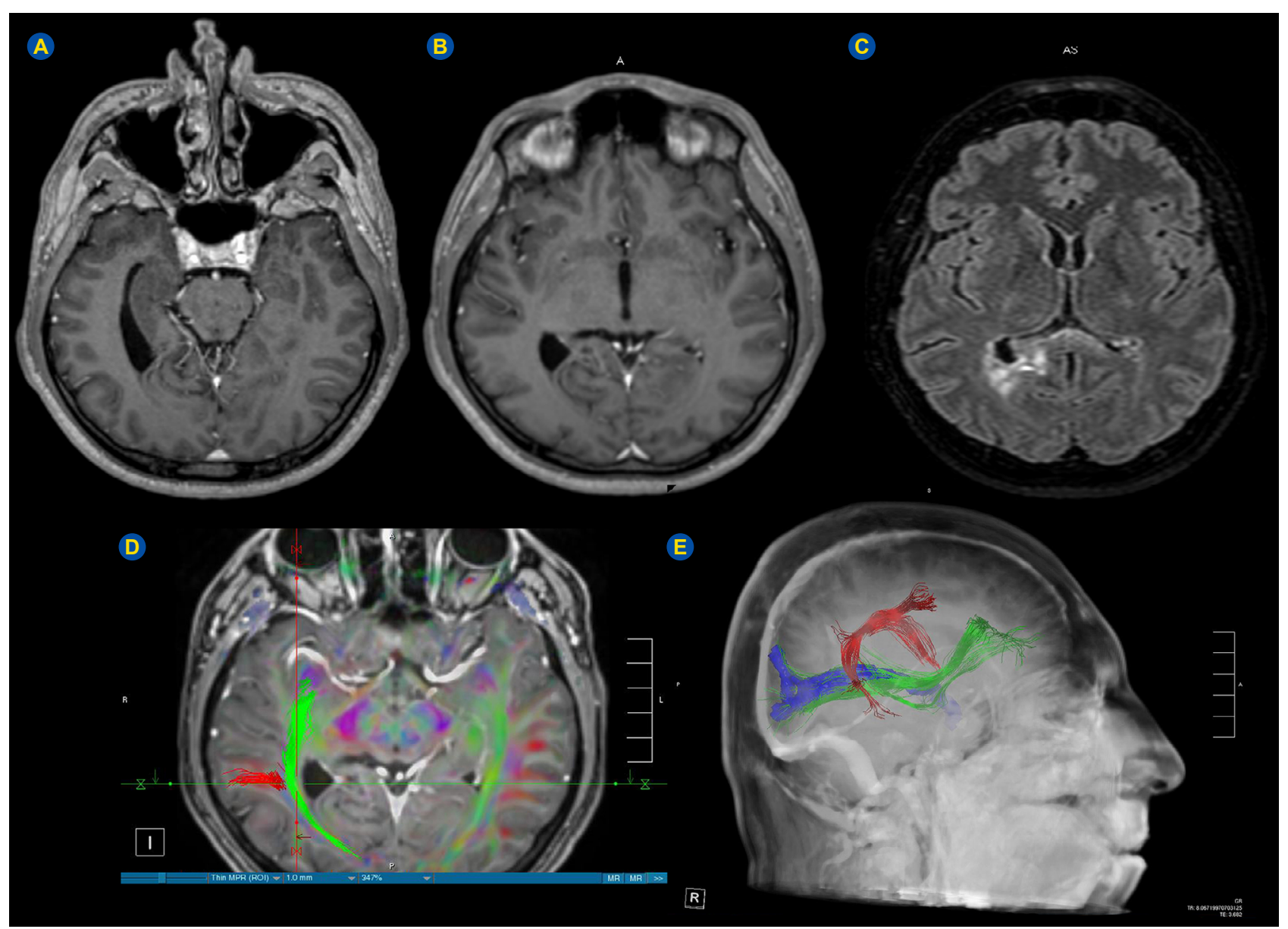

Figure 4 - Post-operative MRI (16 months after surgery). Axial T1-weighted MRI with gadolinium (A-B), axial FLAIR MRI (C), optic radiations tractography fused with T1-weighted Gad (D), 3D reconstruction of arcuate fascicle (red), optic radiations (blue), IFOF (green). No residual tumor is evident after surgery and hippocampus, thalamus, fornix and main white matter tracts lateral to atrium are preserved.

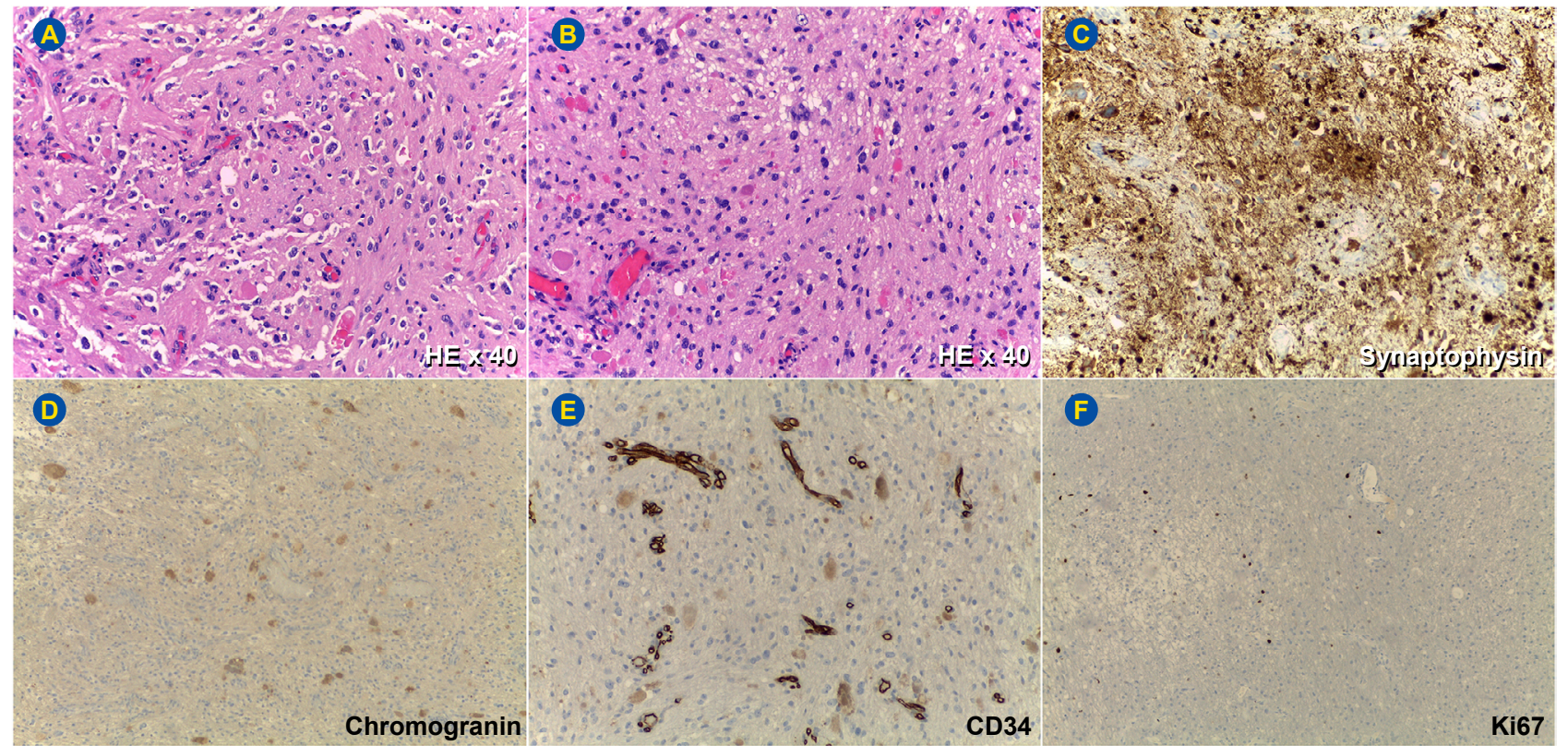

Figure 5 - The first image (A) highlights the neuronal component - several ganglionar cells, in different stages of maturation, are seen. The second image (B) ilustrates the glial component, which recapitulates a pilocytic astrocytoma (note the readily apparent Rosenthal fibers and eosinophilic granular bodies). The next three images (C-E) dysplay imunohistochemical staining of the neuronal component: chromogranin and synaptophysin are usual markers of these cells, and CD34 is aberrantly expressed in gangliogliomas. The last image $(F)$ is Ki67 staining: is extremely low, as one would expect in this setting (under $2 \%$ ). 

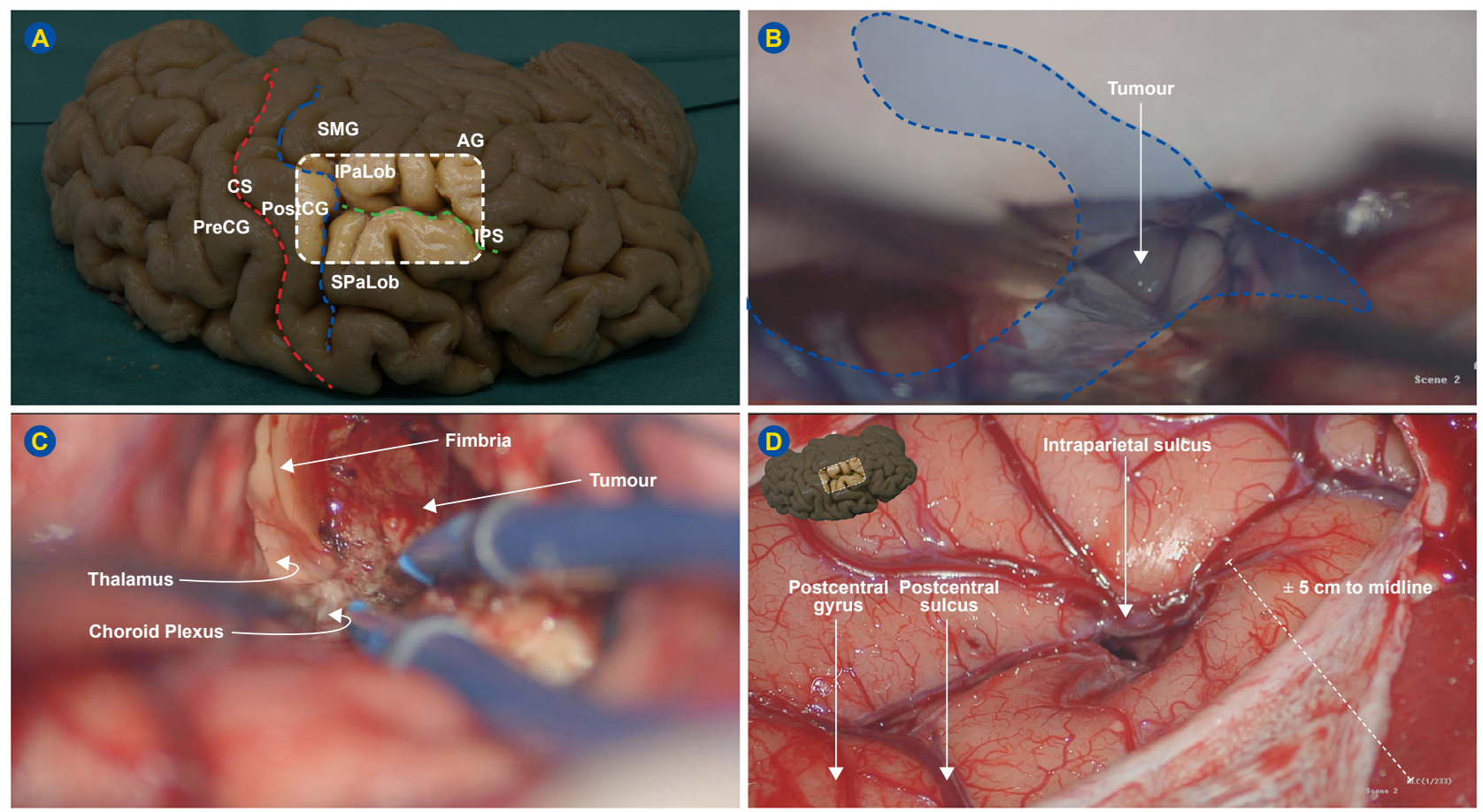

Figure 6 - Right hemisphere labelled to demonstrate craniotomy (white interrupted line), central sulcus (red interrupted line), post-central sulcus (blue interrupted line), intraparietal sulcus (green interrupted line - our access route) (A); intraoperative view of the tumor after splitting the intraparietal sulcus with lateral ventricle represented in blue shade with interrupted line (B); intraoperative view after removing part of the tumor. Thalamus, choroid plexus, fimbria and tumor are labelled $(C)$; final intraoperative view labelled. Minimal collateral damage is observed after tumor removal (D). Anterior-posterior and inferior-superior orientation is represented on top right corner (B-D). SMG: supramarginal gyrus; AG: angular gyrus; IPaLob: inferior parietal lobe; SPaLob: superior parietal lobe; PreCG: pre-central gyrus; CS:- central sulcus; IPS: intraparietal sulcus

\title{
Intraventricular Ganglioglioma Presenting With Spontaneous Hemorrhage
}

\author{
Alexandre Rainha Campos, MD \\ Neurosurgery \\ CUF Descobertas Hospital \\ Lisbon, Portugal - 2015
}

Video 1 - Video illustrating main steps of the operation, beginning with a hemisphere used to illustrate surface anatomy of this region. Sulci and gyri are identified with labels. During removal of the tumor, major anatomical landmarks are also labeled. At the end of the surgery the ventricle is rinsed with warm lactate.

Red dotted line - CS: central sulcus; blue dotted line - post-central sulcus; green dotted line - IPS: intraparietal sulcus; PreCG: precentral gyrus; PostCG: postcentral gyrus; SPaLob: superior parietal lobule; IPaLob: inferior parietal lobule; SMG: supramarginal gyrus; AG: angular gyrus; A: anterior; P: posterior; I: inferior; S: superior; HC: hippocampus; ChPlex: choroidal plexus 
and he is seizure-free (Engel la), with a total recovery of his visual function since surgery.

Post-operative serial MRI showed complete removal of the tumor with discrete hyper signal on T2 and FLAIR in the splenium of corpus callosum without gadolinium enhancement (Fig. 4).

\section{DISCUSSION}

The primary goal of surgery in gangliogliomas presenting with seizures is to cure epilepsy. To obtain this, a total removal of the tumor must be performed..$^{1-4}$ Being a grade I tumor, a total removal is also the best treatment. ${ }^{1-4}$ In this patient, the neurological signs and symptoms were caused by the intra-tumoral hemorrhage. With a gross total removal of the tumor, the three main objectives of the surgery were achieved: oncological cure, epilepsy control and resolution of neurologic deficits.

Brain tractography is a valuable tool that can be integrated to compatible navigation systems, even with injection of fiber tracts and segmented anatomy in surgical microscope ocular. The surgical microscope image becomes this way improved with patients' anatomy in an augmented reality environment. This tool can be used by the neurosurgeon to plan and to guide surgeries. All this information can be used to increase safety during brain surgery.

These tools have been proving their efficacy during surgical planning, increasing safety in the removal of different lesions from cerebrum and brainstem. ${ }^{11-15}$ This case-report is an example of its utility.

The trans intraparietal sulcus approach to lesions located in the atrium allows a safe surgical route without injuring the main fiber tracts. The approach is described in this report with the help of advanced MRI techniques. The alternative lateral approach would most likely injure those important fibers. Instead of improving visual field deficits, this patient could suffer from a permanent hemianopia and some neuropsychological deficits.

Neurosurgeons should be encouraged to use tractography as a planning tool for surgery because it can improve the approach to lesions without injuring important white matter tracts. ${ }^{12-14}$ The integration of this additional information in navigation systems highlights these invisible structures, with expected improvement in patient's outcomes.

\section{ACKNOWLEDGMENTS}

We would like to thank Cláudia Coelho Faria of the Department of Neurosurgery, Hospital de Santa Maria, Centro Hospitalar Lisboa Norte, EPE, Lisbon, Portugal, for valuable comments on the manuscript. She offered assistance without any form of compensation.

\section{PROTECTION OF HUMANS AND ANIMALS}

The authors declare that the procedures were followed according to the regulations established by the Clinical Research and Ethics Committee and to the Helsinki Declaration of the World Medical Association.

\section{DATA CONFIDENTIALITY}

The authors declare that they followed the protocols in use at their working center regarding patients' data publication. Patient consent obtained.

\section{CONFLICTS OF INTEREST}

The authors declare that there are no conflicts of interest.

\section{FUNDING SOURCES}

No subsidies or grants contributed to this work.

\section{REFERENCES}

1. Blümcke I, Wiestler OD. Gangliogliomas: an intriguing tumor entity associated with focal epilepsies. J Neuropathol Exp Neurol. 2002;61:575-84.

2. Campos AR, Clusmann H, Lehe Von M, Niehusmann P, Becker AJ, Schramm J, et al. Simple and complex dysembryoplastic neuroepithelial tumors (DNT) variants: clinical profile, MRI, and histopathology. Neuroradiology. 2009;51:433-43.

3. Luyken C, Blümcke I, Fimmers R, Urbach H, Elger CE, Wiestler OD, et al. The spectrum of long-term epilepsy-associated tumors: longterm seizure and tumor outcome and neurosurgical aspects. Epilepsia. 2003;44:822-30.

4. Urbach H. MRI of long-term epilepsy-associated tumors. Semin Ultrasound CT MR. 2008;29:40-6.

5. Im SH, Chung CK, Cho BK, Wang KC, Yu IK, Song IC, et al. Intracranial ganglioglioma: preoperative characteristics and oncologic outcome after surgery. J Neurooncol. 2002;59:173-83.

6. Bhat D, Mahadevan A, Manish R, Sampath S, Chandramouli BA, Shankar SK. Intraventricular ganglioglioma with bleed: a rare case report. Neurol India. 2010;58:477.

7. Prasad GL, Kumar R, Kurwale N, Suri V. Intraventricular gangliogliomas: a review. World Neurosurg. 2016;87:39-44.

8. Faquini I, Fonseca R, de Melo SV, Negri H, Vieira E, Saboia T, et al. Trigone ventricular meningiomas: Is it possible to achieve good results even in the absence of high tech tools? Surg Neurol Int. 2015;6:180.
9. Martino J, de Lucas EM. Subcortical anatomy of the lateral association fascicles of the brain: A review. Clin Anat. 2014;27:563-9.

10. Vaessen MJ, Saj A, Lovblad KO, Gschwind M, Vuilleumier P. Structural white-matter connections mediating distinct behavioral components of spatial neglect in right brain-damaged patients. Cortex. 2016;77:54-68.

11. Faraji AH, Abhinav $K$, Jarbo $K$, Yeh FC, Shin SS, Pathak S, et al. Longitudinal evaluation of corticospinal tract in patients with resected brainstem cavernous malformations using high-definition fiber tractography and diffusion connectometry analysis: preliminary experience. J Neurosurg. 2015;123:1133-44.

12. Fernandez-Miranda JC, Rhoton AL, Alvarez-Linera J, Kakizawa Y, Choi $\mathrm{C}$, de Oliveira EP. Three-dimensional microsurgical and tractographic anatomy of the white matter of the human brain. Neurosurgery. 2008;62:989-1026.

13. Laundre BJ, Jellison BJ, Badie B, Alexander AL, Field AS. Diffusion tensor imaging of the corticospinal tract before and after mass resection as correlated with clinical motor findings: preliminary data. Am J Neuroradiol. 2005;26:791-6.

14. Thudium MO, Campos AR, Urbach $\mathrm{H}$, Clusmann $\mathrm{H}$. The basal temporal approach for mesial temporal surgery: sparing the meyer loop with navigated diffusion tensor tractography. Neurosurgery. 2010;67:385-90.

15. Mandelli ML, Berger MS, Bucci M, Berman JI, Amirbekian B, Henry RG. Quantifying accuracy and precision of diffusion MR tractography of the corticospinal tract in brain tumors. J Neurosurg. 2014;121:349-58. 